\title{
High performance lithium-sulfur batteries with a facile and effective dual functional separator
}

\author{
Zhangxiang Hao, Lixia Yuan, ${ }^{*}$ Zhen Li, Jing Liu, Jingwei Xiang, Chao Wu, Rui Zeng, \\ Yunhui Huang*
}

State Key Laboratory of Material Processing and Die \& Mould Technology, School of Materials Science and Engineering, Huazhong University of Science and Technology, Wuhan, Hubei 430074, China

*Corresponding author. Tel.: +86 27 87558241. E-mail: yuanlixia@hust.edu.cn (L.X. Yuan); huangyh@hust.edu.cn (Y.H. Huang).

\begin{abstract}
Lithium-sulfur (Li-S) batteries stand as an important candidate for next-generation high-energy secondary batteries due to its high specific capacity, low cost and environmental friendliness. However, practical application of Li-S batteries suffers from low rechargeability, poor rate capability and cycling instability of sulfur cathode, which can be mainly ascribed to the poor conductivity of sulfur and the dissolution of the intermediate polysulfides generated during discharge-charge cycles. In this work, a Nafion/super P-modified dual functional separator is designed to improve the long-term cycle stability and rate capability of the pure sulfur cathode. The electrostatic repulsion between the $\mathrm{SO}_{3}{ }^{-}$groups and the dissolved negative $\mathrm{S}_{\mathrm{n}}{ }^{2-}$ ions, and the trap and reutilizing effect of super $\mathrm{P}$ for polysulfides, provide double insurance to confine the polysulfides within the cathode side, leading to great


improvement in both reversible capacity and cycling stability of the sulfur cathode as compared to the battery with pristine Celgard separator. With such dual functional separator, a simple elemental sulfur cathode with $70 \%$ S content delivers a high initial discharge capacity of $1087 \mathrm{mAh} \mathrm{g}^{-1}$ at $0.1 \mathrm{C}$ and a long-term cyclability with only $0.22 \%$ capacity fade per cycle over 250 cycles at $0.5 \mathrm{C}$.

KEYWORDS: Nafion/super P-modified separator, pure sulfur cathode, long cycle, Li-S batteries

\section{Introduction}

Li-S batteries provide electricity by reducing elemental sulfur to $\mathrm{Li}_{2} \mathrm{~S}$ during discharge [1-4]. The two-electrons redox reaction brings a high theoretical capacity of $1672 \mathrm{Ah} \mathrm{kg}^{-1}$ and a high theoretical energy density of $2600 \mathrm{Wh} \mathrm{kg}^{-1}$, almost 6 times larger than those of current lithium-ion battery [5-7]. As one of the most potential candidates for next-generation high-energy rechargeable batteries, the Li-S battery has gained increasing attention in recent years $[8,9]$. However, the commercial application of Li-S batteries is largely plagued by the low utilization of active material and the short cycling lifespan of sulfur cathode, which are mainly caused by the insulating nature of elemental sulfur and the diffusion of the dissolved intermediate long-chain polysulfides in organic electrolyte during charge-discharge process. In addition, the density difference between sulfur and the final discharge product $\left(\mathrm{Li}_{2} \mathrm{~S}\right)$ brings a volume expansion of $80 \%$ during lithiation process, which may cause structure collapse of the cathode and thus result in the deterioration of battery performances. 
Besides, the type and quantity of polysulfides vary with the state of charge-discharge, and the electrolyte composition changes accordingly, leading to an uncertainty of the solid electrolyte interface (SEI) on $\mathrm{Li}$ anode surface which is also responsible for the performance degradation in Li-S batteries.

Many efforts have been done to solve the problems. At current stage, the main strategy to solve the problems is to design various composite nanostructures. Various nanostructured carbon materials, like meso/microporous carbon spheres [10-12], activated carbon nanofibers [13-15], carbon nanotubes [16-20] and graphenes [21-26], have been widely utilized as conductive hosts to encapsulate elemental sulfur and cage polysulfides within the porous frameworks. More recently, a new strategy, trapping polysulfides within the cathode via chemical process, was reported. Some metal oxides $\left(\mathrm{MnO}_{2}, \mathrm{Ti}_{4} \mathrm{O}_{7}\right)$ [27-31], MXene nanosheets $\left(\mathrm{Ti}_{2} \mathrm{C}\right)$ [32], metal organic frameworks (MOFs) [33-36], have been proved to be able to immobilize polysulfides via chemical interaction.

Although great progress has been achieved, it is still difficult to prevent the loss of dissolved $\mathrm{S}_{\mathrm{n}}{ }^{2-}$ completely. The conversion processes from elemental sulfur (solid) to dissolved intermediate $\mathrm{Li}_{2} \mathrm{~S}_{\mathrm{n}}$ (liquid) and from $\mathrm{Li}_{2} \mathrm{~S}_{\mathrm{n}}$ (liquid) to the final reduction products $\mathrm{Li}_{2} \mathrm{~S}_{2} / \mathrm{Li}_{2} \mathrm{~S}$ (solid) accompany with the liquid electrolyte's penetration in and out of the matrix. Despite the physical/chemical interaction between $\mathrm{S}_{\mathrm{n}}{ }^{2-}$ and the host, a certain amount of $\mathrm{S}_{\mathrm{n}}{ }^{2-}$ ions will escape from the "physical and/or chemical cage" inevitably along with the repeated "solid $\rightarrow$ liquid $\rightarrow$ solid" phase change. So, it is very difficult to totally immobilize sulfur species via the isolated structure design for 
cathode materials. In addition, the fabrication of the nanostructured porous carbon hosts and mesoporous oxides additives usually demands elaborate procedures, involving high-temperature process and complicated template-deleting process. These requirements can largely limit the mass product ability of the sulfur composite cathode materials.

On the other hand, battery is a complicated system for the cathode, anode and electrolyte interact with each other. The interactions in the Li-S system are much stronger and more complicated than other lithium battery systems due to the soluble intermediate polysulfides. Compared with the isolated structure design of sulfur cathode materials, the modification of electrolyte [37] or developing functional membranes [38,39] may provide more effective approach for improving the electrochemical performance of $\mathrm{Li}-\mathrm{S}$ batteries. For example, $\mathrm{LiNO}_{3}$ can form a stable passivation film on the surface of the lithium anode and therefore effectively suppress the redox shuttle effect of polysulfides and maintain a high Coulombic efficiency of Li-S batteries [40-43]. Now $\mathrm{LiNO}_{3}$ has been widely employed as electrolyte additive in the Li-S system. The solvent-in-salt electrolyte system shows great competence in suppressing lithium dendrite growth in the metallic lithium anode and inhibiting lithium polysulfide dissolution [37]. A lithiated Nafion ionomer membrane instead of common membrane (Celgard 2400) was first reported as functional separator for Li-S batteries in 2012, which can act as an electrostatic shield for polysulfide anions, and confine the polysulfides on the cathode side because the $\mathrm{SO}_{3}{ }^{-}$groups-coated channels allow $\mathrm{Li}^{+}$ion hopping but reject the negative $\mathrm{S}_{\mathrm{n}}{ }^{2-}$ ions due to Coulombic interactions 
[44]. In addition to modifying the membrane, a similar electrostatic shield could also be established via Nafion-coated sulfur cathode [45-47] or Nafion-coated separator to constrain the polysulfides within the cathode side [48]. Manthiram's group also reported a composite cathode structure containing AC-CNF current collector filled with lithium polysulfides and Nafion membrane to enhance the electrochemical performance of Li-S battery [49]. More recently, a kind of ternary-Layered separator was prepared via integrating polypropylene, graphene oxide and Nafion [50] to retard the shuttle of polysulfides for Li-S batteries.

In this work, a novel dual-functional separator was developed for the Li-S battery via a simple coating process. A mixture of Nafion and super $\mathrm{P}$ was coated on the cathode side. In this system, the $\mathrm{SO}_{3}{ }^{-}$groups in Nafion offers an electrostatic shield to block the polysulfides, while super $\mathrm{P}$, which is adsorptive and electronic conductive, provides physical trap to obstruct the diffusion of polysulfides and meanwhile acts as an accessorial current collector to further reutilize the diffused polysulfides. Both of them form double insurance to confine the polysulfides within the cathode side. With this modified separator, a sulfur cathode prepared by commercial elemental sulfur with 70 wt.\% sulfur content, reveals a high initial reversible capacity of $1087 \mathrm{mAh} \mathrm{g}^{-1}$ at $0.1 \mathrm{C}$ and a long-term charge/discharge process of 250 cycles at $0.5 \mathrm{C}$, with a cycle decay value of $0.22 \%$ per cycle.

\section{Experimental}

2.1. Fabrication of Nafion/super P-modified separator and pure sulfur cathode A Nafion/super P slurry was prepared by mixing 45 wt.\% super P, 45 wt.\% 
Nafion solution (5 wt.\%, Sigma-Aldrich), 5 wt.\% carboxyl methyl cellulose sodium salt (NaCMC), and 5 wt.\% styrene butadiene rubber (SBR) in deionized water to form homogeneous slurry. This slurry was coated on one side of commercial Celgard separator by a glass rod, and then dried in a vacuum oven at $80{ }^{\circ} \mathrm{C}$ for $6 \mathrm{~h}$. After drying, the Nafion/super P-modified separator was cut into wafers with diameter of 18 $\mathrm{mm}$ for cell assembly. The lithiation process of Nafion/super P-modified separator was carried out as the previous report [48].

The sulfur cathode was prepared by mixing commercial sulfur powder, super $\mathrm{P}$, NaCMC, and SBR in a weight ratio of $70: 20: 5: 5$ in deionized water. The slurry was coated on aluminum (Al) foil and dried at $80{ }^{\circ} \mathrm{C}$ overnight in a vacuum oven. Finally, the electrode was roll pressed, and punched into round discs with a diameter of $8 \mathrm{~mm}$. The sulfur mass loading in the cathode was more than $1 \mathrm{mg} \mathrm{cm}^{-2}$.

\subsection{Electrochemical measurements}

CR 2032 type coin cells were assembled and sealed in an Ar-filled glove box with routine Celgard 2300 separator and Nafion/super P-modified membrane, respectively. A solution of $1 \mathrm{~mol} \mathrm{~L}{ }^{-1}$ LiTFSI in mixed 1, 2-dimethoxyethane (DME) and 1, 3-dioxolane (DOL) (1:1 v/v) containing $\mathrm{LiNO}_{3}(1 \mathrm{wt} . \%)$ served as electrolyte. The electrolyte amount added in the coin cell was $30 \mu \mathrm{L}$. A lithium metal was utilized as anode. Cyclic voltammogram (CV) measurement was carried out on an electrochemical workstation (CHI614b) at a scan rate of $0.1 \mathrm{mV} \mathrm{s}^{-1}$ with a cutoff voltage of $1.7-2.8 \mathrm{~V}$ at room temperature. Galvanostatic charge and discharge were tested on a battery measurement system (Land, China). Electrochemical impedance 
spectroscopy (EIS) was measured in the frequency range from $0.01 \mathrm{~Hz}$ to $100 \mathrm{kHz}$ (PARSTAT 2273, Princeton).

\subsection{Characterization}

The morphologies of the Celgard membrane and Nafion/super P-modified separator were characterized by scanning electron microscopy (SEM, FEI, Sirion200), and the elemental composition was checked by energy dispersive X-ray spectroscopy (EDX).

A homemade U-type glass tube was used to examine the "blocking" effect of the separators for dissolved polysulfides. The Celgard membranes with and without Nafion/super P modification were placed in the middle of the U-type glass tube. The mass loading of the Nafion and super P composites on the separator was about 0.15 $\mathrm{mg} \mathrm{cm}{ }^{-2}$, which was the same with those used for electrochemical testing. The left side of the U-type glass tube was filled with pure tetrahydrofuran (THF) and the right side owned the THF solution with $5 \mathrm{mg} \mathrm{mL}^{-1} \mathrm{Li}_{2} \mathrm{~S}_{4}$. The whole experiment was carried out in a glove box to exclude the impact of oxygen and water. Finally, the diffusion of polysulfides from right to left through the separator was recorded by a common optical camera.

\section{Result and discussion}

Fig. 1 illustrates the cell configuration with the Nafion/super P-modified separator, where the coating layer is set to face to the sulfur cathode. In addition to the routine function that maintains the feature of $\mathrm{Li}^{+}$ionic pathway and blocks the electrons transfer between the anode and cathode electrodes, the Nafion/super 
P-coated membrane also works as ionic shield to intercept the leaked polysulfides before they diffuse to the anode side because the $\mathrm{SO}_{3}{ }^{-}$groups-coated channels can allow $\mathrm{Li}^{+}$ions hopping but reject the negative $\mathrm{S}_{\mathrm{n}}{ }^{2-}$ ions due to Coulombic interactions, and as an accessorial conductive current collector to trap and reutilize them due to the physical obstruction and conductive nature of super P.

The original separator (Celgard 2300) has a smooth surface with regular channels throughout, as shown in Fig. $2 \mathrm{a}$ and $2 \mathrm{~b}$. The diameter of the pores is around $400 \mathrm{~nm}$. Fig. 2d and 2e show the SEM images of surface of Nafion/super P-modified separator. It can be clearly seen that a dense coating layer, containing interweaved and nanosize Nafion and super $\mathrm{P}$ particles, attaches to one side of the original Celgard separator covering the original nanopores. In this modified separator, the original insulating porous Celgard PP membrane plays the basic function of a separator in the cell that splits the direct contact of the cathode and anode. After filling with electrolyte, it can prevent the transfer of electrons but maintain the ionic pathway. The cross-section image in Fig. $2 \mathrm{c}$ shows the original Celgard separator is $\sim 25 \mu \mathrm{m}$ thick, and the thickness of the Nafion and super P layer is $\sim 3 \mu \mathrm{m}$ (Fig. 2f). The mass loading of the modifier layer is $\sim 0.15 \mathrm{mg} \mathrm{cm}^{-2}$. The EDX pattern of Nafion/super P-modified separator (Fig. 3) shows two new peaks of $\mathrm{F}$ and $\mathrm{S}$ due to the Nafion containing $\mathrm{F}$ and S elements, indicating the homogeneous distribution of the Nafion molecules in the mixture coating layer. The Pt element originates from the sample preparation of spraying Pt.

To evaluate the "blocking effect" of the Nafion/super P-modified separator on 
the polysulfides, the coin cells with both the modified separator and a routine elemental sulfur cathode were tested. Fig. 4a shows CV curves for the cell with Nafion/super P-coated separator at a scan rate of $0.1 \mathrm{mV} \mathrm{s}^{-1}$. The cathodic peaks at 2.33 and $2.05 \mathrm{~V}$ correspond to the reduction of elemental sulfur from $\mathrm{S}_{8}$ to higher-order polysulfides $\left(\mathrm{Li}_{2} \mathrm{~S}_{x}, x=4-8\right)$, and then to lower-order $\mathrm{Li}_{2} \mathrm{~S}_{2} / \mathrm{Li}_{2} \mathrm{~S}$. In the subsequent anodic process, two oxidation peaks are observed at 2.35 and $2.38 \mathrm{~V}$, which are attributed to the reverse reaction of $\mathrm{Li}_{2} \mathrm{~S}_{2} / \mathrm{Li}_{2} \mathrm{~S}$ to higher-order polysulfides $\left(\mathrm{Li}_{2} \mathrm{~S}_{x}, x=4-8\right)$, then to sulfur, respectively. In the results, the curves for the first 5 cycles are almost overlapped with each other, indicative of good cycle stability. Fig. 4b shows the discharge-charge profiles at different cycles. The voltage-capacity curves show two discharge plateaus located at 2.2 and $2.05 \mathrm{~V}$, two adjacent charge plateaus at 2.3 and $2.4 \mathrm{~V}$, which are well consistent with the CV curves. Obviously, the coating of Nafion/super P has no negative influence on the kinetic reactions of sulfur species.

Fig. 5a compares the rate performance of the two kinds of cells with different separators. For the cell with Nafion/super P-modified separator, it delivers discharge capacities of 1067, 930, 807 and $302 \mathrm{mAh} \mathrm{g}^{-1}$ at $0.1,0.2,0.5$ and $1 \mathrm{C}$, respectively, much higher than those of the cell with routine Celgard separator (478, 299, 197 and $158 \mathrm{mAh} \mathrm{g}^{-1}$ at $0.1,0.2,0.5$ and $\left.1 \mathrm{C}\right)$. When the charge/discharge rate is returned to $0.1 \mathrm{C}$ after running for 20 cycles at high rates, a reversible capacity of $1040 \mathrm{mAh} \mathrm{g}^{-1}$ is recovered, corresponding a capacity retention of $97.5 \%$, while the routine cell can be only recovered to less than $370 \mathrm{mAh} \mathrm{g}^{-1}$ ( $\sim 77 \%$ retention). Fig. $5 \mathrm{~b}$ shows the 
voltage-specific capacity curves at different current densities for the cell with coated separator. The charge/discharge plateaus rise/drop with increasing current density, but two discharge plateaus maintain well. The cyclability of the cell with Nafion/super P-modified separator at various currents is shown in Fig. 5c. After 100 cycles, the cell still maintains reversible capacities of 741,649 and $549 \mathrm{mAh} \mathrm{g}^{-1}$ at $0.1,0.2$ and $0.5 \mathrm{C}$, respectively. Fig. $5 \mathrm{~d}$ shows the long cycle performance at $0.5 \mathrm{C}$. With $70 \mathrm{wt} . \%$ sulfur content and more than $1.5 \mathrm{mg} \mathrm{cm}^{-2}$ mass loading, the Li-S battery with a routine Celgard separator only delivers an initial discharge capacity of $552 \mathrm{mAh} \mathrm{g}^{-1}$ and retains only $180 \mathrm{mAh} \mathrm{g}^{-1}$ after 250 cycles at $0.5 \mathrm{C}$. For the cell with Nafion/super P-modified separator, it achieves an initial capacity of $863 \mathrm{mAh} \mathrm{g}^{-1}$ and reversible capacity of $430 \mathrm{mAh} \mathrm{g}^{-1}$ after 250 cycles, displaying a largely improved capacity retention and cycle stability. Moreover, the modified separator reduces the capacity fading to only $0.22 \%$ per cycle at $0.5 \mathrm{C}$. During the charge-discharge cycles, both of the two cells show high Coulombic efficiencies in the range of $95-100 \%$.

The "blocking and trap" effect of Nafion/super P-modified separator has also been visually proved by a direct and simple test, as shown in Fig. 6. Two "U" tubes were divided into two parts by the separator. The left colorless transparent liquid is pure THF solvent, and the right yellow liquid is THF solution with polysulfides $\left(\mathrm{Li}_{2} \mathrm{~S}_{4}\right)$. The right side solutions in the two " $\mathrm{U}$ " tubes have the same $\mathrm{Li}_{2} \mathrm{~S}_{4}$ concentration. As shown in Fig. 6a-c, the color of the pure THF liquid in left glass tube gradually turns to yellow after 120 minutes, indicating that the polysulfides in the right glass tube diffuse through the routine Celgard separator. In contrast, there is no 
obvious color change for the "U" tube with the modified separator (Fig. 6d-f), implying that the Nafion/super P-modified separator successfully acts as a highly efficient polysulfide barrier.

To get further insight into the electrode process in the cell, EIS was tested with frequency from $0.01 \mathrm{~Hz}$ to $100 \mathrm{kHz}$. As presented in Fig. 7a, the cell with original separator displays a depressed semicircle in high and an inclined line in low frequency ranges, representing the charge transfer resistance and Warburg impedance, respectively. While the cell with Nafion/super P-modified separator represent two depressed semicircles in high and medium frequency, followed by an inclined line in low frequency. The additional semicircle can be related with the Nafion/super P coated layer on the membrane. Fig. $7 \mathrm{~b}$ and $7 \mathrm{c}$ show the equivalent circuits for the cells with routine Celgard separator and Nafion/super P-modified separator, respectively. In the equivalent circuit, $R_{1}$ stands for the solution resistance, $R_{2}$ the interface electrochemical reaction resistance, and $R_{3}$ the geometry resistance for the extra Nafion/super P layer. Here the CPE1 is used instead of double-layer capacitance, and CPE2 describes the space charge capacitance of the Nafion/super P layer. And $W_{\mathrm{o} 1}$ is the Warburg impedance due to the diffusion of the polysulfides within the cathode side. The main simulation results for the main parameters are listed in Table 1. The most noticeable difference between these two batteries system is the great difference between the electrochemical reaction resistance $\left(R_{2}\right)$, which decreases from 55.4 to $32.5 \Omega \mathrm{cm}^{-2}$ when the Nafion/super P-modified separator was used instead the routine one. This should be benefited from the conductive super P in the coated layer 
that can work as an extended current collector to reutilize the $\mathrm{S}_{\mathrm{n}}{ }^{2-}$ leaked from the sulfur cathode. Because the redox reaction of $\mathrm{S}_{\mathrm{n}}{ }^{2-}$ in the Nafion/super P layer is the same as that in the cathode, it is also reflected by $R_{2}$ in Fig. 7c. The significantly reduced $R_{2}$ can explain the better rate performance for the cell with Nafion/super P-modified separator. The faint difference between two $R_{1}$ values (7.5 and $13.2 \Omega$ $\mathrm{cm}^{-2}$ ) can be also ascribed to the Nafion/super P layer. The layer largely keeps the $\mathrm{S}_{\mathrm{n}}{ }^{2-}$ ions within the cathode side, leading to some difference of the $\mathrm{S}_{\mathrm{n}}{ }^{2-}$ content between electrolytes in the two systems.

\section{Conclusions}

In summary, a novel dual-functional separator has been successfully fabricated via a simple coating of Nafion and super $\mathrm{P}$ mixture on a routine Celgard separator. With this modified separator, a sulfur cathode (commercial elemental sulfur, $70 \% \mathrm{~S}$ content, $\sim 1.5 \mathrm{mg} \mathrm{cm}^{-2}$ mass loading) can achieve high initial reversible discharge capacity (1087 $\left.\mathrm{mAh} \mathrm{g}^{-1}\right)$, long-term cycle life (250 cycles), and excellent reversibility ( $0.22 \%$ capacity fade per cycle). This outstanding performance can be attributed to double insurance provided by Nafion/super P-modified separator to confine the polysulfides within the cathode side. The electrostatic shield built by Nafion can block the electronegative $\mathrm{S}_{\mathrm{n}}{ }^{2-}$ ions via electrostatic repulsion, while the trapping and reutilizing effects of super $\mathrm{P}$ due to its adsorptive and conductive nature can further promote the performance. The present strategy shows a simple promising way for high-performance Li-S batteries. 


\section{Acknowledgments}

This work was supported by the 973 program (Grant No. 2015CB258400), and the National Science Foundation of China (Grant Nos.21273087 and 21271078). The authors acknowledge the Analytical and Testing Center of HUST for FESEM measurement.

\section{References}

[1] P.G. Bruce, S.A. Freunberger, L.J. Hardwick, J.M. Tarascon, Li-O ${ }_{2}$ and Li-S batteries with high energy storage, Nat. Mater. 11 (2012) 19-29.

[2] L. Chen, L.L. Shaw, Recent advances in lithium-sulfur batteries, J. Power Sources 267 (2014) 770-783.

[3] A. Manthiram, S.H. Chung, C. Zu, Lithium-sulfur batteries: progress and prospects, Adv. Mater. 27 (2015) 1980-2006.

[4] J.-Q. Huang, Q. Zhang, F. Wei, Multi-functional separator/interlayer system for high-stable lithium-sulfur batteries: Progress and prospects, Energy Storage Materials 1 (2015) 127-145.

[5] B. Wu, X. Jiang, L. Xiao, W. Zhang, J. Pan, X. Ai, H. Yang, Y. Cao, Enhanced cycling stability of sulfur cathode surface-modified by poly(n-methylpyrrole), Electrochimica Acta 135 (2014) 108-113.

[6] H. Nagata, Y. Chikusa, A lithium sulfur battery with high power density, J. Power Sources 264 (2014) 206-210.

[7] Y. Zhao, Y. Ding, Y. Li, L. Peng, H.R. Byon, J.B. Goodenough, G. Yu, A chemistry and material perspective on lithium redox flow batteries towards high-density electrical energy storage, Chem. Soc. Rev. 44 (2015) 7968-7996.

[8] A. Manthiram, Y. Fu, S.H. Chung, C. Zu, Y.S. Su, Rechargeable lithium-sulfur batteries, Chem. Rev. 114 (2014) 11751-11787. 
[9] J. Scheers, S. Fantini, P. Johansson, A review of electrolytes for lithium-sulphur batteries, J. Power Sources 255 (2014) 204-218.

[10] S.E. G. He, X. Liang, M. Cuisinier, A. Garsuch, and L.F. Nazar, Tailoring porosity in carbon nanospheres for lithium-sulfur battery cathodes, ACS Nano 7 (2013) 10920-10930.

[11] Z. Li, Y. Jiang, L. Yuan, Z. Yi, C. Wu, Y. Liu, P. Strasser, Y. Huang, A highly ordered meso@microporous carbon-supported sulfur@smaller sulfur core-shell structured cathode for li-s batteries, ACS Nano 8 (2014) 9295-9303.

[12] Z. Wang, S. Zhang, L. Zhang, R. Lin, X. Wu, H. Fang, Y. Ren, Hollow spherical carbonized polypyrrole/sulfur composite cathode materials for lithium/sulfur cells with long cycle life, J. Power Sources 248 (2014) 337-342.

[13] L. Zeng, F. Pan, W. Li, Y. Jiang, X. Zhong, Y. Yu, Free-standing porous carbon nanofibers-sulfur composite for flexible li-s battery cathode, Nanoscale 6 (2014) 9579-9687.

[14] G. Zheng, Q. Zhang, J.J. Cha, Y. Yang, W. Li, Z.W. Seh, Y. Cui, Amphiphilic surface modification of hollow carbon nanofibers for improved cycle life of lithium sulfur batteries, Nano lett. 13 (2013) 1265-1270.

[15] Z. Zhao, D. Qin, S. Wang, G. Chen, Z. Li, Fabrication of high conductive s/c cathode by sulfur infiltration into hierarchical porous carbon/carbon fiber weave-structured materials via vapor-melting method, Electrochimica Acta 127 (2014) 123-131.

[16] Y. Zhao, W. Wu, J. Li, Z. Xu, L. Guan, Encapsulating mwnts into hollow porous carbon nanotubes: A tube-in-tube carbon nanostructure for high-performance lithium-sulfur batteries, Adv. Mater. 26 (2014) 5113-5118.

[17] C. Tang, Q. Zhang, M.Q. Zhao, J.Q. Huang, X.B. Cheng, G.L. Tian, H.J. Peng, F. Wei, Nitrogen-doped aligned carbon nanotube/graphene sandwiches: Facile catalytic growth on bifunctional natural catalysts and their applications as scaffolds for high-rate lithium-sulfur batteries, Adv. Mater. 26 (2014) 6100-6105. 
[18] L. Wang, Y. Zhao, M.L. Thomas, H.R. Byon, In situ synthesis of bipyramidal sulfur with $3 \mathrm{~d}$ carbon nanotube framework for lithium-sulfur batteries, Adv. Funct. Mater. 24 (2014) 2248-2252.

[19] Y. Zhang, Y. Zhao, Z. Bakenov, M. Tuiyebayeva, A. Konarov, P. Chen, Synthesis of hierarchical porous sulfur/polypyrrole/multiwalled carbon nanotube composite cathode for lithium batteries, Electrochimica Acta 143 (2014) 49-55.

[20] Z. Li, J.T. Zhang, Y.M. Chen, J. Li, X.W. Lou, Pie-like electrode design for high-energy density lithium-sulfur batteries, Nat. Commun. 6 (2015) 8850.

[21] H. Zhao, Z. Peng, W. Wang, X. Chen, J. Fang, J. Xu, Reduced graphene oxide with ultrahigh conductivity as carbon coating layer for high performance sulfur@ reduced graphene oxide cathode, J. Power Sources 245 (2014) 529-536.

[22] L. Ji, M. Rao, H. Zheng, L. Zhang, Y. Li, W. Duan, J. Guo, E.J. Cairns, Y. Zhang, Graphene oxide as a sulfur immobilizer in high performance lithium/sulfur cells, J. Am. Chem. Soc. 133 (2011) 18522-18525.

[23] Z. Wang, Y. Dong, H. Li, Z. Zhao, H.B. Wu, C. Hao, S. Liu, J. Qiu, X.W. Lou, Enhancing lithium-sulphur battery performance by strongly binding the discharge products on amino-functionalized reduced graphene oxide, Nat. Commun. 5 (2014) 5002.

[24] J. Zhang, Z.M. Dong, X.L. Wang, X.Y. Zhao, J.P. Tu, Q.M. Su, G.H. Du, Sulfur nanocrystals anchored graphene composite with highly improved electrochemical performance for lithium-sulfur batteries, J. Power Sources 270 (2014) 1-8.

[25] B. Papandrea, X. Xu, Y. Xu, C.-Y. Chen, Z. Lin, G. Wang, Y. Luo, M. Liu, Y. Huang, L. Mai, X. Duan, Three-dimensional graphene framework with ultra-high sulfur content for a robust lithium-sulfur battery, Nano Research 9 (2016) 240-248. [26] G. Zhou, L. Li, D.W. Wang, X.Y. Shan, S. Pei, F. Li, H.M. Cheng, A flexible sulfur-graphene-polypropylene separator integrated electrode for advanced Li-S batteries, Adv. Mater. 27 (2015) 641-647.

[27] X. Liang, C. Hart, Q. Pang, A. Garsuch, T. Weiss, L.F. Nazar, A highly efficient polysulfide mediator for lithium-sulfur batteries, Nat. Commun. 6 (2015) 5682. 
[28] Z. Li, J. Zhang, X.W. Lou, Hollow carbon nanofibers filled with $\mathrm{MnO}_{2}$ nanosheets as efficient sulfur hosts for lithium-sulfur batteries, Angew. Chem., Int. Ed. 54 (2015) 12886-12890.

[29] X. Tao, J. Wang, Z. Ying, Q. Cai, G. Zheng, Y. Gan, H. Huang, Y. Xia, C. Liang, W. Zhang, Y. Cui, Strong sulfur binding with conducting magneli-phase $\mathrm{Ti}_{\mathrm{n}} \mathrm{O}_{2 \mathrm{n}-1}$ nanomaterials for improving lithium-sulfur batteries, Nano lett. 14 (2014) $5288-5294$.

[30] Q. Pang, D. Kundu, M. Cuisinier, L.F. Nazar, Surface-enhanced redox chemistry of polysulphides on a metallic and polar host for lithium-sulphur batteries, Nat. Commun. 5 (2014) 4759.

[31] S. Wang, Z. Yang, H. Zhang, H. Tan, J. Yu, J. Wu, Mesoporous $\beta-\mathrm{MnO}_{2} / \mathrm{sulfur}$ composite as cathode material for li-s batteries, Electrochimica Acta 106 (2013) 307-311.

[32] X. Liang, A. Garsuch, L.F. Nazar, Sulfur cathodes based on conductive mxene nanosheets for high-performance lithium-sulfur batteries, Angew. Chem., Int. Ed. 54 (2015) 3907-3911.

[33] H.B. Wu, S. Wei, L. Zhang, R. Xu, H.H. Hng, X.W. Lou, Embedding sulfur in mof-derived microporous carbon polyhedrons for lithium-sulfur batteries, Chem.--Eur. J. 19 (2013) 10804-10808.

[34] J. Zheng, J. Tian, D. Wu, M. Gu, W. Xu, C. Wang, F. Gao, M.H. Engelhard, J.G. Zhang, J. Liu, J. Xiao, Lewis acid-base interactions between polysulfides and metal organic framework in lithium sulfur batteries, Nano lett. 14 (2014) 2345-2352.

[35] G. Xu, B. Ding, L. Shen, P. Nie, J. Han, X. Zhang, Sulfur embedded in metal organic framework-derived hierarchically porous carbon nanoplates for high performance lithium-sulfur battery, J. Mater. Chem. A 1 (2013) 4490-4496.

[36] J. Zhang, H. Hu, Z. Li, X.W. Lou, Double-shelled nanocages with cobalt hydroxide inner shell and layered double hydroxides outer shell as high-efficiency polysulfide mediator for lithium-sulfur batteries, Angew. Chem. Int. Ed. (2016) 10.1002/anie.201511632. 
[37] L. Suo, Y.-S. Hu, H. Li, M. Armand, L. Chen, A new class of solvent-in-salt electrolyte for high-energy rechargeable metallic lithium batteries, Nat. Commun. 4 (2013) 1481.

[38] Z. Zhang, Y. Lai, Z. Zhang, K. Zhang, J. Li, $\mathrm{Al}_{2} \mathrm{O}_{3}$-coated porous separator for enhanced electrochemical performance of lithium sulfur batteries, Electrochimica Acta 129 (2014) 55-61.

[39] D. Zhao, X. Qian, L. Jin, X. Yang, S. Wang, X. Shen, S. Yao, D. Rao, Y. Zhou, X. Xi, Separator modified by ketjen black for enhanced electrochemical performance of lithium-sulfur batteries, RSC Adv. 6 (2016) 13680-13685.

[40] S.S. Zhang, Role of $\mathrm{LiNO}_{3}$ in rechargeable lithium/sulfur battery, Electrochim. Acta 70 (2012) 344-348.

[41] X. Liang, Z. Wen, Y. Liu, M. Wu, J. Jin, H. Zhang, X. Wu, Improved cycling performances of lithium sulfur batteries with $\mathrm{LiNO}_{3}$-modified electrolyte, J. Power Sources 196 (2011) 9839-9843.

[42] S.S. Zhang, Effect of discharge cutoff voltage on reversibility of lithium/sulfur batteries with $\mathrm{LiNO}_{3}$-contained electrolyte, J. Electrochem. Soc. 159 (2012) A920-A923.

[43] S. Xiong, K. Xie, Y. Diao, X. Hong, Properties of surface film on lithium anode with $\mathrm{LiNO}_{3}$ as lithium salt in electrolyte solution for lithium-sulfur batteries, Electrochimica Acta 83 (2012) 78-86.

[44] Z. Jin, K. Xie, X. Hong, Z. Hu, X. Liu, Application of lithiated nafion ionomer film as functional separator for lithium sulfur cells, J. Power Sources 218 (2012) 163-167.

[45] J.-Q. Huang, Q. Zhang, H.-J. Peng, X.-Y. Liu, W.-Z. Qian, F. Wei, Ionic shield for polysulfides towards highly-stable lithium-sulfur batteries, Energy Environ. Sci. 7 (2014) 347-353.

[46] J. Song, M.J. Choo, H. Noh, J.K. Park, H.T. Kim, Perfluorinated ionomer-enveloped sulfur cathodes for lithium-sulfur batteries, ChemSusChem 7 (2014) 3341-3346. 
sulfur-carbon electrode for high performance lithium-sulfur batteries, J. Power Sources 246 (2014) 253-259.

[48] I. Bauer, S. Thieme, J. Brückner, H. Althues, S. Kaskel, Reduced polysulfide shuttle in lithium-sulfur batteries using nafion-based separators, J. Power Sources 251 (2014) 417-422.

[49] X. Yu, J. Joseph, A. Manthiram, Polymer lithium-sulfur batteries with a nafion membrane and an advanced sulfur electrode, J. Mater. Chem. A 3 (2015) 15683-15691.

[50] T.Z. Zhuang, J.Q. Huang, H.J. Peng, L.Y. He, X.B. Cheng, C.M. Chen, Q. Zhang, Rational integration of polypropylene/graphene oxide/nafion as ternary-layered separator to retard the shuttle of polysulfides for lithium-sulfur batteries, Small 12 (2016) 381-389. 


\section{Figure Captions}

Fig. 1. Schematic illustration for the Li-S battery with a Nafion/super P-modified separator.

Fig. 2. SEM images of the surface of $(a, b)$ original Celgard separator and $(d, e)$ Nafion/super P-modified separator, and cross-section images of (c) original Celgard separator and (f) Nafion/super P-modified separator.

Fig. 3. EDX of the routine and Nafion/super P-modified separator.

Fig. 4. (a) Initial five cycle curves of $\mathrm{CV}$ at a scan rate of $0.1 \mathrm{mV} \mathrm{s}^{-1}$ with Nafion/super P-modified separator and (b) voltage $v s$. specific capacity profiles at 0.2 C during cycling.

Fig. 5. (a) Discharge capacity at various rates, (b) voltage $v s$. specific capacity profiles at various rates with Nafion/super P-modified separator, (c) cycling performance at 0.1, 0.2 and $0.5 \mathrm{C}$ with Nafion/super P-modified separator, (d) specific capacity and Coulombic efficiency as functions of cycle number at $0.5 \mathrm{C}$.

Fig. 6. The optical photos for diffusion of polysulfides within various period: (a-c) routine Celgard separator, (d-f) Nafion/super P-modified separator.

Fig. 7. (a) Nyquist plots with Nafion/Super P-modified and Celgard separator. Equivalent circuit with (b) Celgard separator and (c) Nafion/super P-modified separator. 
Fig. 1.

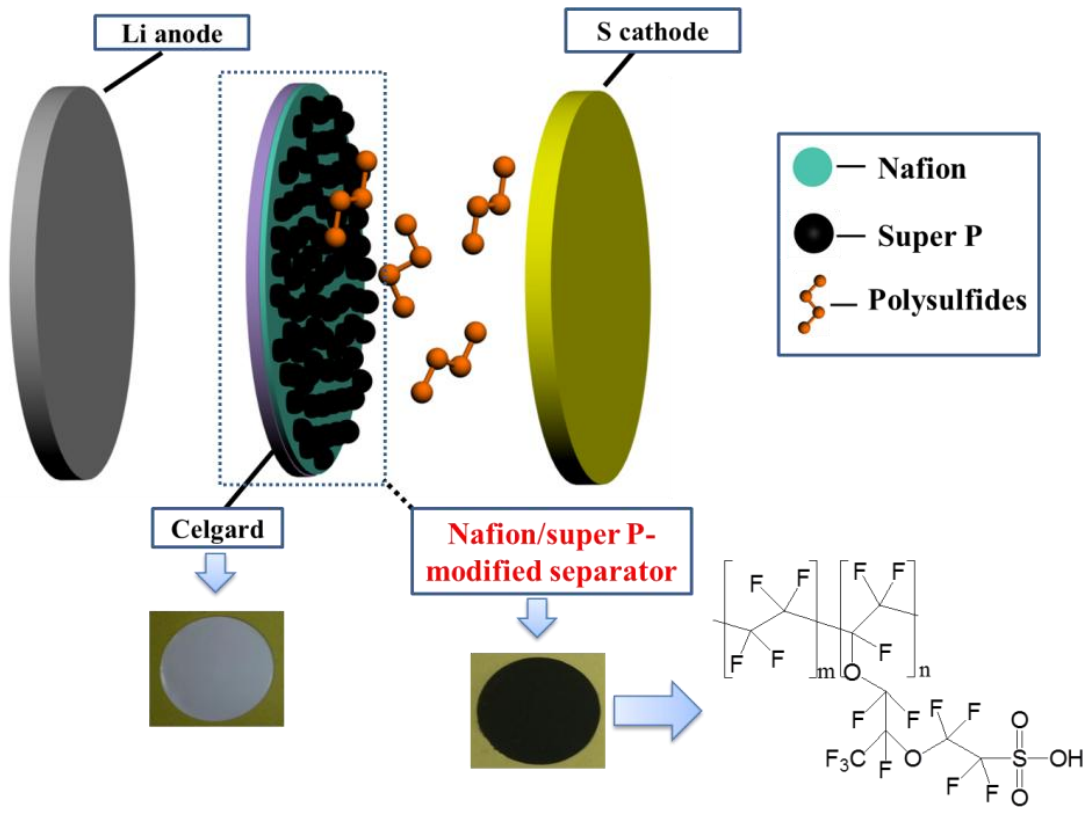

Fig. 2.
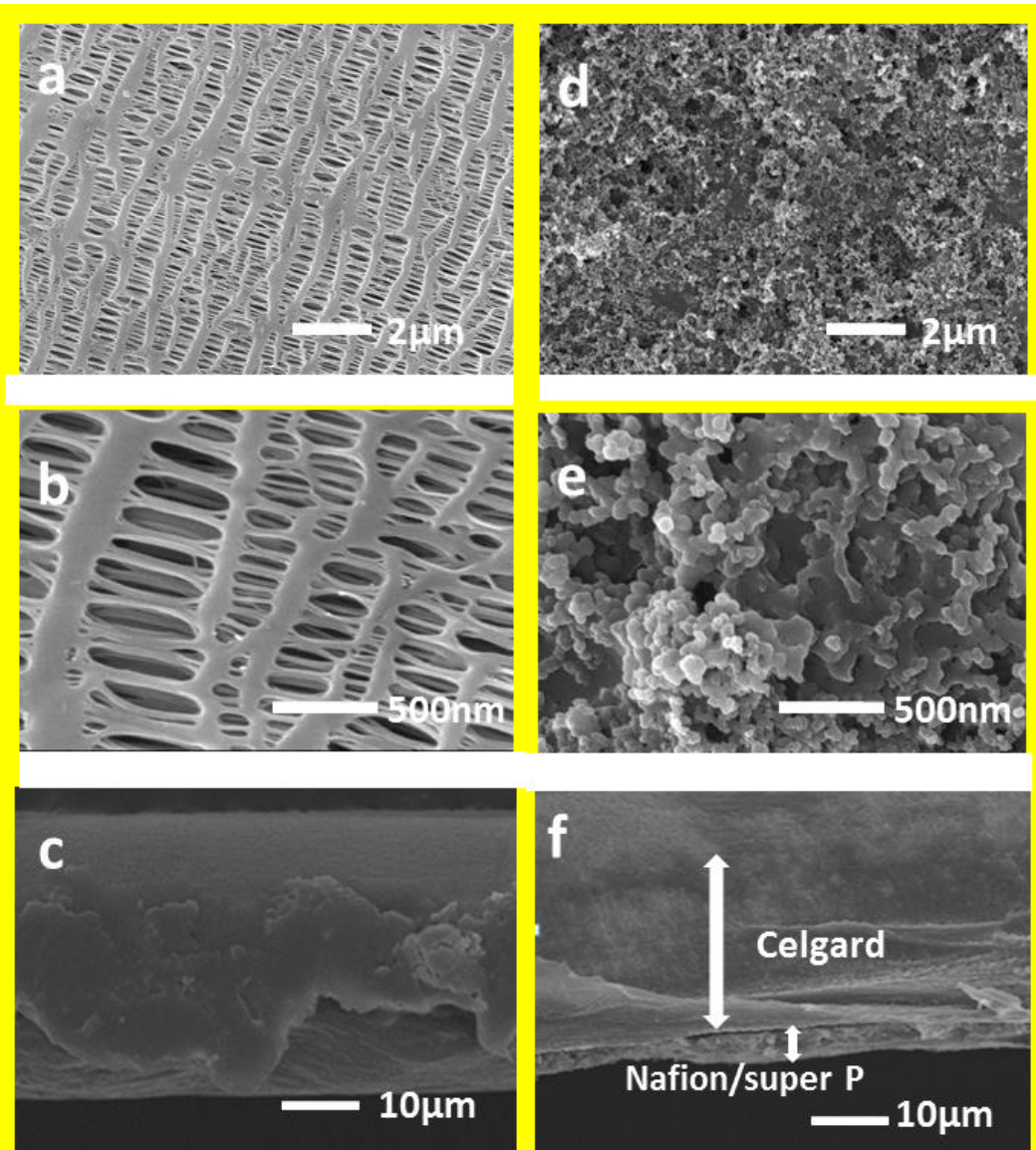
Fig. 3.

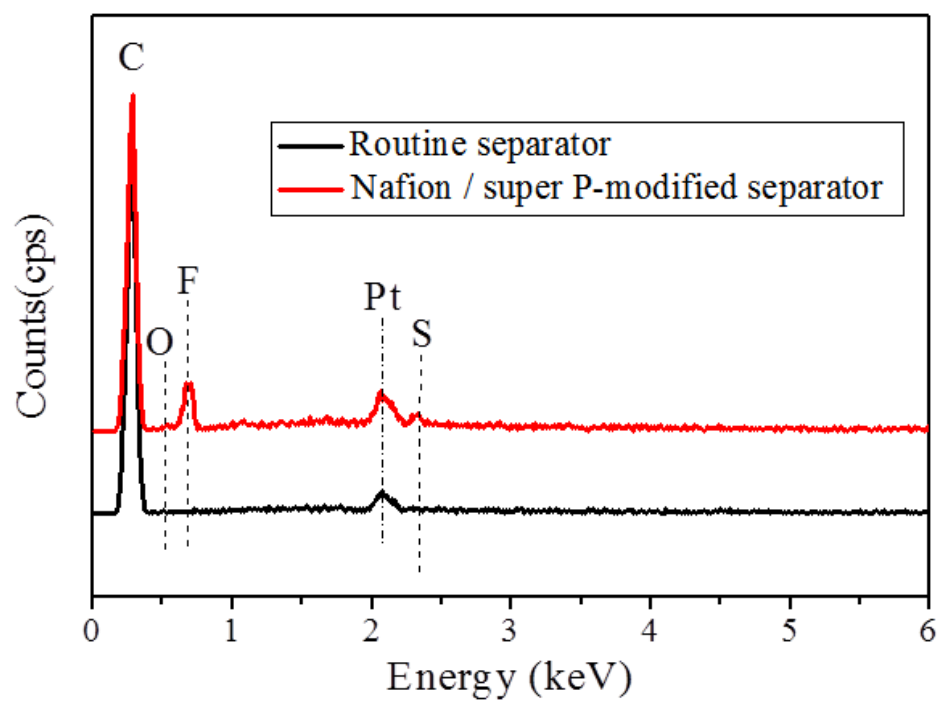

Fig. 4.

(a)

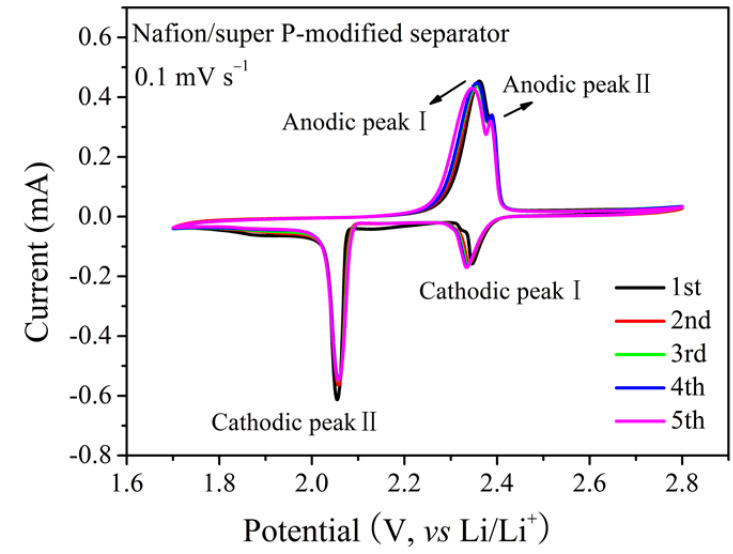

(b)

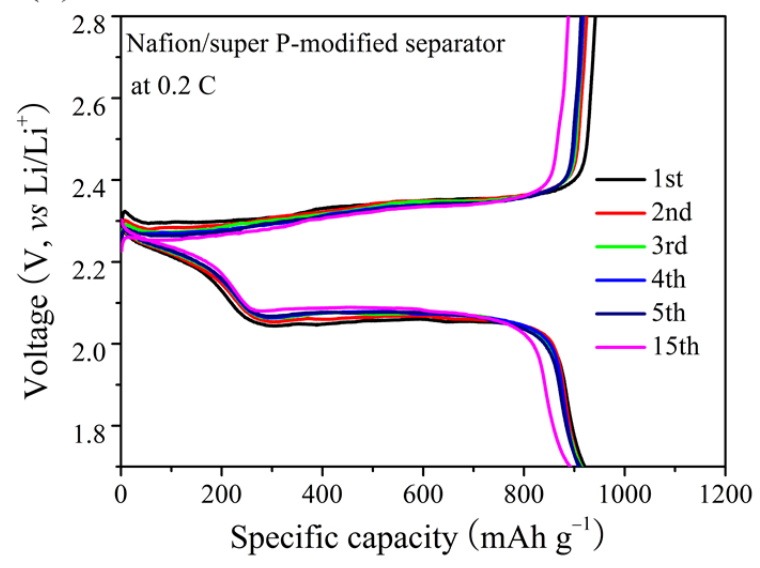


Fig. 5.
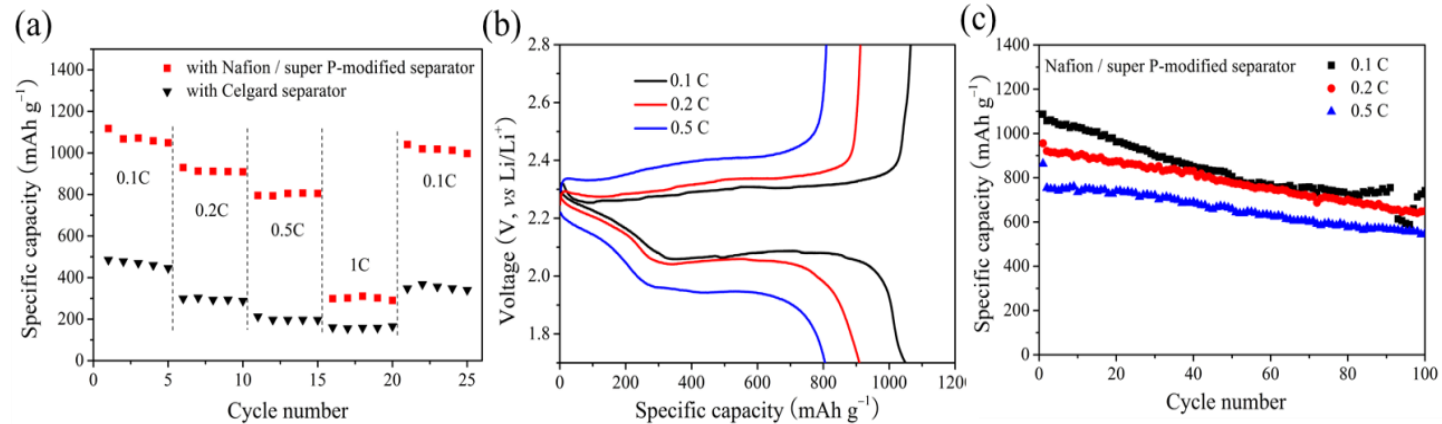

(d)

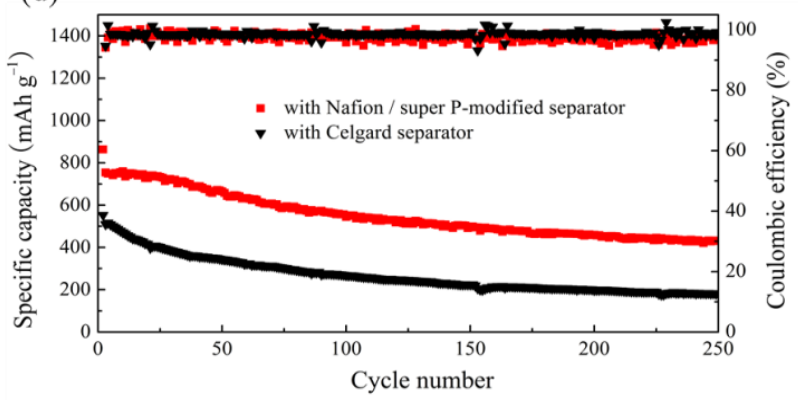

Fig. 6.
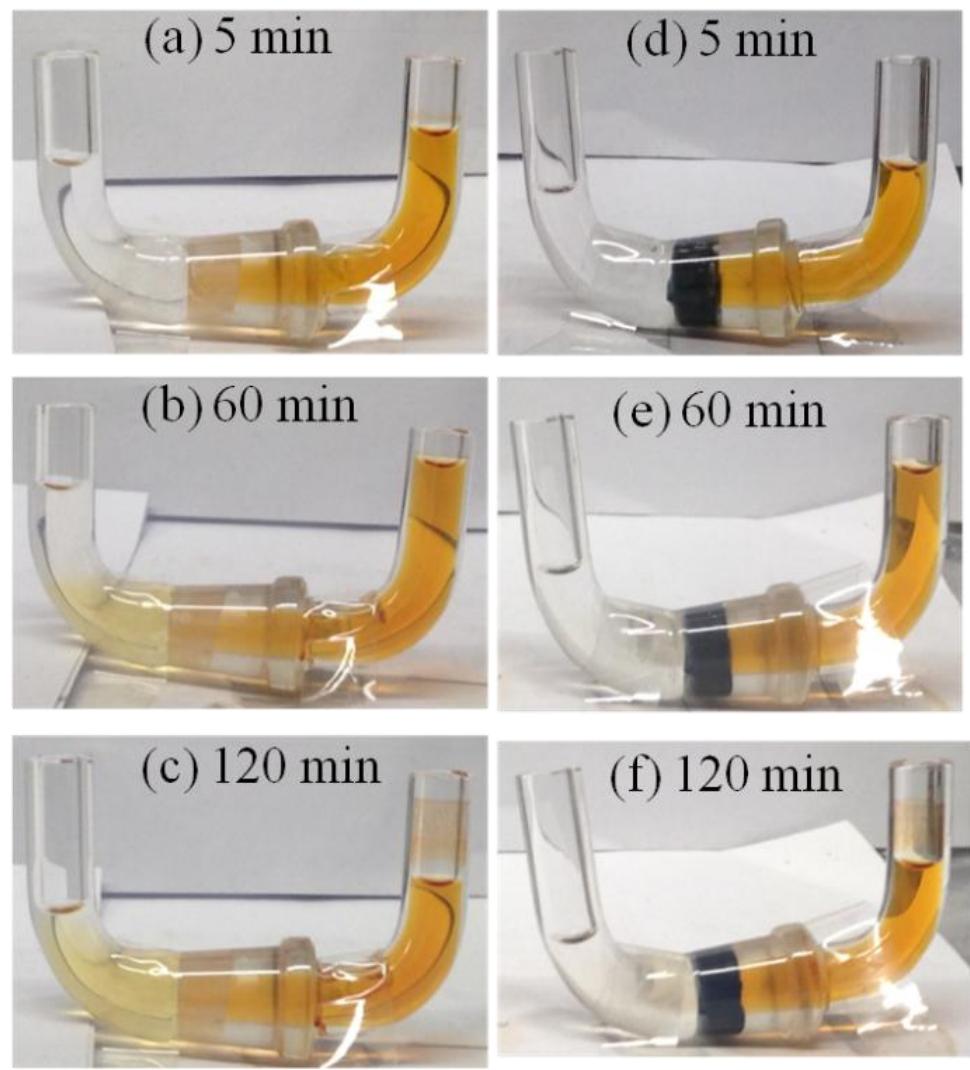
Fig. 7.

(a)

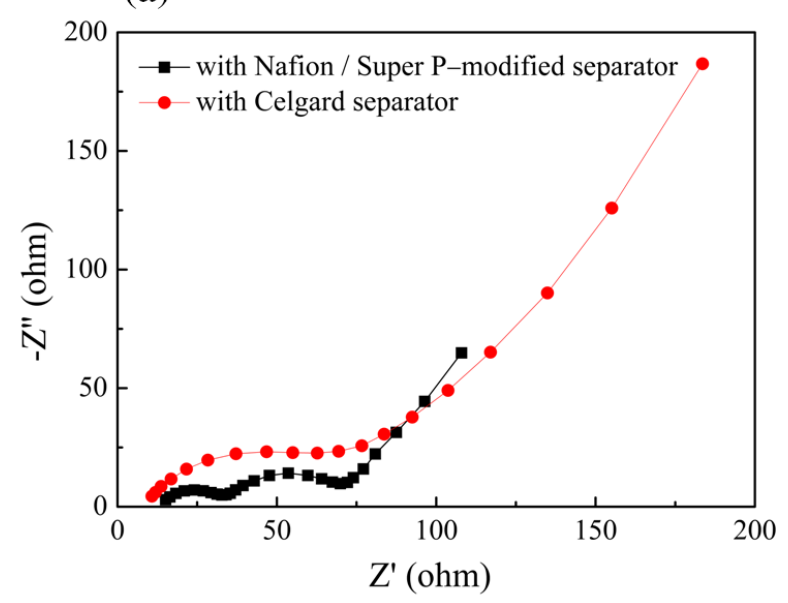

(b)

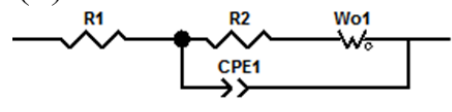

(c)

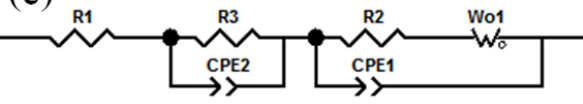


Table 1. The values of $R_{1}, R_{2}$ and $R_{3}$ with Celgard and Nafion/super P-modified separator.

\begin{tabular}{|c|c|c|c|}
\hline & $R_{1}\left(\Omega \mathrm{cm}^{-2}\right)$ & $R_{2}\left(\Omega \mathrm{cm}^{-2}\right)$ & $R_{3}\left(\Omega \mathrm{cm}^{-2}\right)$ \\
\hline $\begin{array}{c}\text { Cell with original Celgard } \\
\text { separator }\end{array}$ & 7.5 & 55.4 & \\
\hline $\begin{array}{c}\text { Cell with Nafion/super } \\
\text { P-modified separator }\end{array}$ & 13.2 & 32.5 & 21.5 \\
\hline
\end{tabular}

